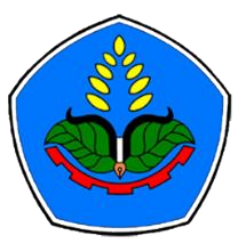

AGROPROSS

National Conference

Proceedings of Agriculture

\section{Conference:}

Implementasi IPTEKS Sub Sektor Perkebunan Pendukung

Devisa Negara dan Ketahanan Energi Indonesia

Tempat : Gedung Pascasarjana, Politeknik Negeri Jember

Tanggal : 18-19 September 2019

\section{Proceedings Series:}

Agropross : National Conference Proceedings of Agriculture

DOI : 10.25047/agropross.2019.89

\title{
Analisis Potensi Lahan Desa Tanah Wulan Kecamatan Maesan Kabupaten Bondowoso Untuk Perkebunan Kopi Arabika dan Kopi Robusta
}

\author{
Author(s): Mohamad Hamid Mamud Hanafi( ${ }^{(1)}$; Elida Novita*(1); Idah Andriyani ${ }^{(1)}$ \\ (1) Universitas Jember, Indonesia \\ * Corresponding author: elida_novita.ftp@unej.ac.id
}

\begin{abstract}
Tanah Wulan Village, Maesan District, Bondowoso Regency is one of the villages on the slopes of the Argopuro mountains. The majority of the population in Tanah Wulan Village work as coffee farmers. The community coffee plantation in Tanah Wulan Village is located on Perhutani land with a height of between 600-1300 m above sea level. The purpose of this study is to determine the potential land for Arabica and Robusta coffee plants, determine the status of land management for coffee cultivation in Tanah Wulan Village, and determine the suitability of soil types for coffee cultivation in Tanah Wulan Village. The method used is the analysis of the altitude and slope of the forest location using geographic information systems. The results of the analysis of coffee plantations using geographic information system methods produce maps that contain some information. The information is in the form of land locations that have the potential to be used as Arabica and Robusta coffee plantations. Information about the condition of the land is presented in the form of a map of land potential that can be used as a reference for opening new land for coffee plantations. From the results of the analysis of land potential, it is found that the potential land yield for Arabica coffee plantations is only managed by 49\% while for Robusta land it has been managed as much as $95 \%$.
\end{abstract}

\section{Kata Kunci: \\ Kopi; \\ Perkebunan;}

\section{ABSTRAK} Desa Tanah Wulan Kecamatan Maesan Kabupaten Bondowoso merupakan salah satu desa yang berada di lereng pegunungan Argopuro. Mayoritas penduduk di Desa Tanah Wulan berkerja

Potensi Lahan; sebagai petani kopi. Perkebunan kopi rakyat di Desa Tanah Wulan terletak lahan perhutani dengan ketinggian antara 600-1300 m dpl. Tujuan penelitian ini yaitu untuk mengetahui potensi lahan untuk tanaman kopi arabika dan kopi robusta, mengetahui status pengelolaan lahan untuk budidaya kopi di Desa Tanah Wulan, dan mengetahui kesesuaian jenis tanah untuk budidaya kopi di Desa Tanah Wulan. Metode yang digunakan yaitu dengan analisis ketinggian dan kelerengan lokasi perkebuanan dengan menggunakan sistem informasi geografis. Hasil dari analisis perkebunan kopi menggunakan metode sistem informasi geografis menghasilkan peta yang memuat beberapa informasi. Informasi tersebut berupa lokasi lahan yang berpotensi untuk dijadikan kebun kopi arabika dan robusta. Informasi tentang kondisi lahan tersebut disajikan dalam bentuk peta potensi lahan yang dapat dijakan sebagai acuan untuk membuka lahan baru untuk dijakan kebun kopi. Dari hasil analisis potensi lahan didapatkan hasil lahan yang berpotensi untuk perkebunan kopi arabika hanya terkelola sebanyak 49\% sedangkan untuk lahan robusta sudah dikelola sebanyak 95\%. 


\section{PENDAHULUAN}

Indonesia terletak di daerah tropis yang menyebabkan Indonesia dikaruniai kekayaan sumberdaya alam (SDA) yang sangat beragam. Negara ini juga memiliki tanah subur yang terdapat di hampir seluruh wilayahnya. Kekayaan SDA tersebut banyak dimanfaatkan penduduknya sebagai mata pencaharian. Bentuk dari mata pencaharian yang banyak memanfaatkan SDA tersebut yaitu pertanian dan perkebunan. Berbagai komoditas pertanian dan perkebunan dapat dengan mudah dibudidayakan di Indonesia. Komoditas pertanian dan perkebunan penting di Indonesia meliputi beras, jagung, minyak sawit, karet, kakao, kopi, teh dan rempah-rempah tropis.

Kopi merupakan salah satu komoditi penting bagi perekonomian di Indonesia. Saat ini Indonesia merupakan penghasil kopi terbesar ketiga di dunia. Kopi banyak ditanam oleh masyarakat karena perawatannya yang mudah. Pada umumnya kopi yang dibudidayakan yaitu jenis kopi arabika dan kopi robusta. Kedua jenis tersebut memiliki karakteristik yang berdeda. Kopi robusta lebih mudah untuk dibudidayakan daripada kopi arabika, sedangkan kopi arabika memiliki nilai ekonomi yang lebih tinggi daripada kopi robusta (Kementrian perdagangan, 2018).

Seperti tanaman pada umumnya tanaman kopi juga memiliki syarat untuk tumbuh. Tanaman kopi akan tumbuh dan menghasilkan produk yang optimal jika ditanam pada daerah yang sesuai dengan syarat tumbuhnya. Syarat tumbuh kopi arabika antara lain dapat ditanam pada ketinggian lebih dari $1000 \mathrm{~m} \mathrm{dpl}$, tetapi ketinggian optimal adalah $1000-1500 \mathrm{~m}$ dpl dengan temperatur rata-rata antara $17^{\circ} \mathrm{C}-21^{\circ} \mathrm{C}$ (Syamsulbahri. 1985). Syarat tumbuh kopi robusta antara lain dapat ditanam pada ketinggian 0-1000 m dpl, tetapi ketinggian optimal adalah 400-800 $\mathrm{m}$ dpl dengan temperatur rata-rata antara $21{ }^{\circ} \mathrm{C}-24{ }^{\circ} \mathrm{C}$ (Mulyana, 1982). Selain ketinggian tanaman kopi akan tumbuh optimal jika ditanam di tanah dengan tekstur lempung atau liat (Supriadi, 2017).

Salah satu daerah penghasil kopi di Indonesia yaitu kabupaten Bondowoso. Desa Tanah Wulan merupakan salah satu desa di Kecamatan Maesan Kabupaten Bondowoso yang terletak di lereng pegunungan Argopuro. Mayoritas penduduk desa Tanah Wulan bermata pencaharian sebagai petani kopi. Desa Tanah Wulan terletak pada 113,669174 s/d 113,769604 LS dan $-7,968185 \mathrm{~s} / \mathrm{d}$ 8,032615 BT dengan ketinggian antara 300 $-2650 \mathrm{~m}$ dpl. Kebanyakan kebun kopi di desa Tanah Wulan berada pada lahan hutan perhutani Kabupaten Bondowoso.

Kegiatan pembukaan lahan baru merupakan salah satu bentuk kegiatan yang dilakukan masyarakat untuk meningkatkan hasil panen kopi. Perlunya analisis potensi lahan Desa Tanah Wulan bertujuan agar pembukaan lahan baru untuk kebun kopi berada pada lahan yang sesuai dan ramah lingkungan.

\section{METODE PENELITIAN}

Metode yang digunakan dalam penelitian ini yaitu survey lapang dan pengolahan data primer. Survey lapang bertujuan untuk mengetahui secara langsung kondisi perkebunan kopi dan untuk menentukan lokasi dari perkebunan kopi sedangkan pengolahan data primer digunakan untuk menentukan potensi lahan desa Tanah Wulan. Metode analisis data dalam penelitian ini menggunakan metode analisis data spasial dengan teknologi GIS. Analisis spasial mengunakan data primer untuk menentukan potensi lahan berdasarkan pada parameter ketinggian, kelerengan, dan jenis tanah.

Bahan yang digunakan untuk penelitian ini meliputi titik koordinat kebun kopi, peta RBI, data kontur Kabupaten Bondowoso, peta jenis tanah, dan image satelit desa Tanah Wulan. Untuk alat yang digunakan meliputi GPS, 
Komputer, software Mapinfo, dan Microsoft excel.

Berikut merupakan parameter yang digunakan untuk menentukan lokasi lahan yang berpotensi untuk dijadikan perkebunan kopi

a) Ketinggian (elevasi)

Ketinggian lahan merupakan posisi vertical suatu lokasi yang diukur secara tegak lurus dengan tinggi permukaan air laut. Ketinggian yang yang dikehendaki oleh tanaman kopi yaitu $0-1000 \mathrm{~m} \mathrm{dpl}$ untuk jenis kopi robusta dan $>1000 \mathrm{~m} \mathrm{dpl}$ untuk jenis kopi arabika (Syamsulbahri, 1985).

b) Kelerengan

Kemiringan lereng adalah sudut rerata antara bidang datar (bidang semu) dipermukaan bumi terhadap suatu garis atau bidang miring yang ditarik dari titik terendah sampai titik tertinggi dipermukaan bumi pada suatu bentuk lahan, yang merupakan satu kesatuan. tanaman kopi dapat ditanam pada lahan yang memiliki kelerenagan $<45 \%$. Lahan dengan kelerengan $>45 \%$ sebaiknya diutamakan untuk dijadikan sebagai hutan (Supriadi, 2017).

c) Jenis Tanah

Tanah merupakan media tumbuh bagi tanaman. Jenis tanah sangat beraneka ragam dan memiliki karakteristik yang berbeda-beda. Tanaman kopi akan tumbuh subur pada media tanah dengan karakteristik memiliki tekstur lempung dan liat (Supriadi, 2017).

Cara kerja pembuatan peta potensi lahan disajikan dalam flowchart dibawa ini.

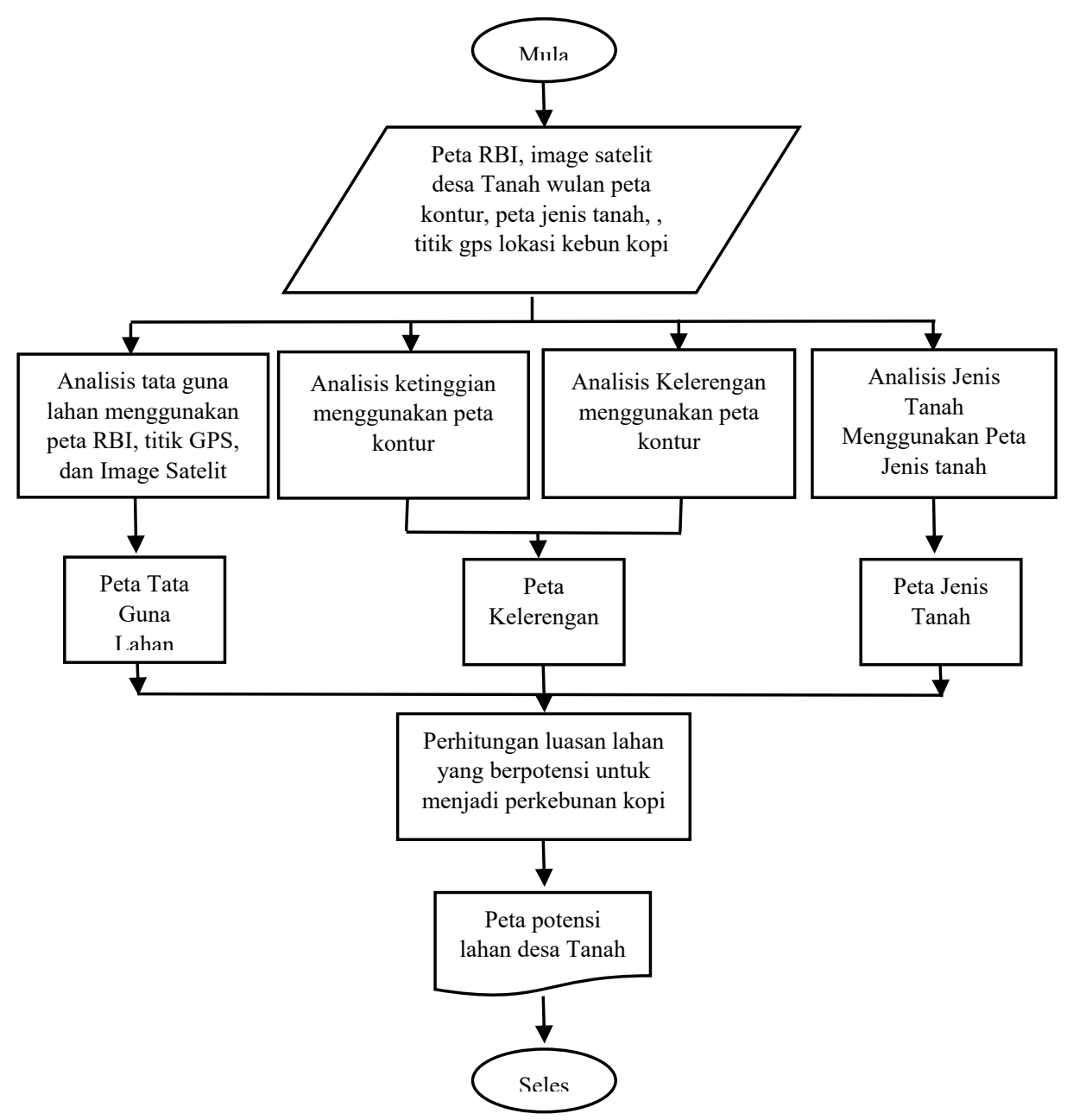

Gamabar 1. Cara Kerja Pembuatan Peta Potensi Lahan 
Peta potensi lahan merupakan hasil overlay dari peta ketinggian, peta kelerengan, dan peta jenis tanah. Peta ketinggian dan kelerengan merupakan hasil interpolasi dari data kontur dan diguanakan untuk mengidentifikasi lokasi lahan yang sesuai dan sekaigus untuk membatasi daerah dengan kelerengan lebih dari $45 \%$. Peta jenis tanah digunakan untuk mengidentifikasi kesesuaian tanah desa Tanah Wulan untuk tanaman kopi.

\section{HASIL DAN PEMBAHASAN}

Potensi lahan dapat ditentukan dari beberapa parameter, parameter yang digunakan untuk analisis potensi lahan desa Tanah Wulan untuk Tanaman kopi yaitu parameter ketinggian, kelerengan, dan jenis tanah. Informasi tentang potensi lahan untuk tanaman kopi di desa Tanah Wulan merupakan acuan dalam menentukan lokasi kebun kopi yang sesuai dengan memperhatikan faktor ketinggian, kelerengan, dan jenis tanah.

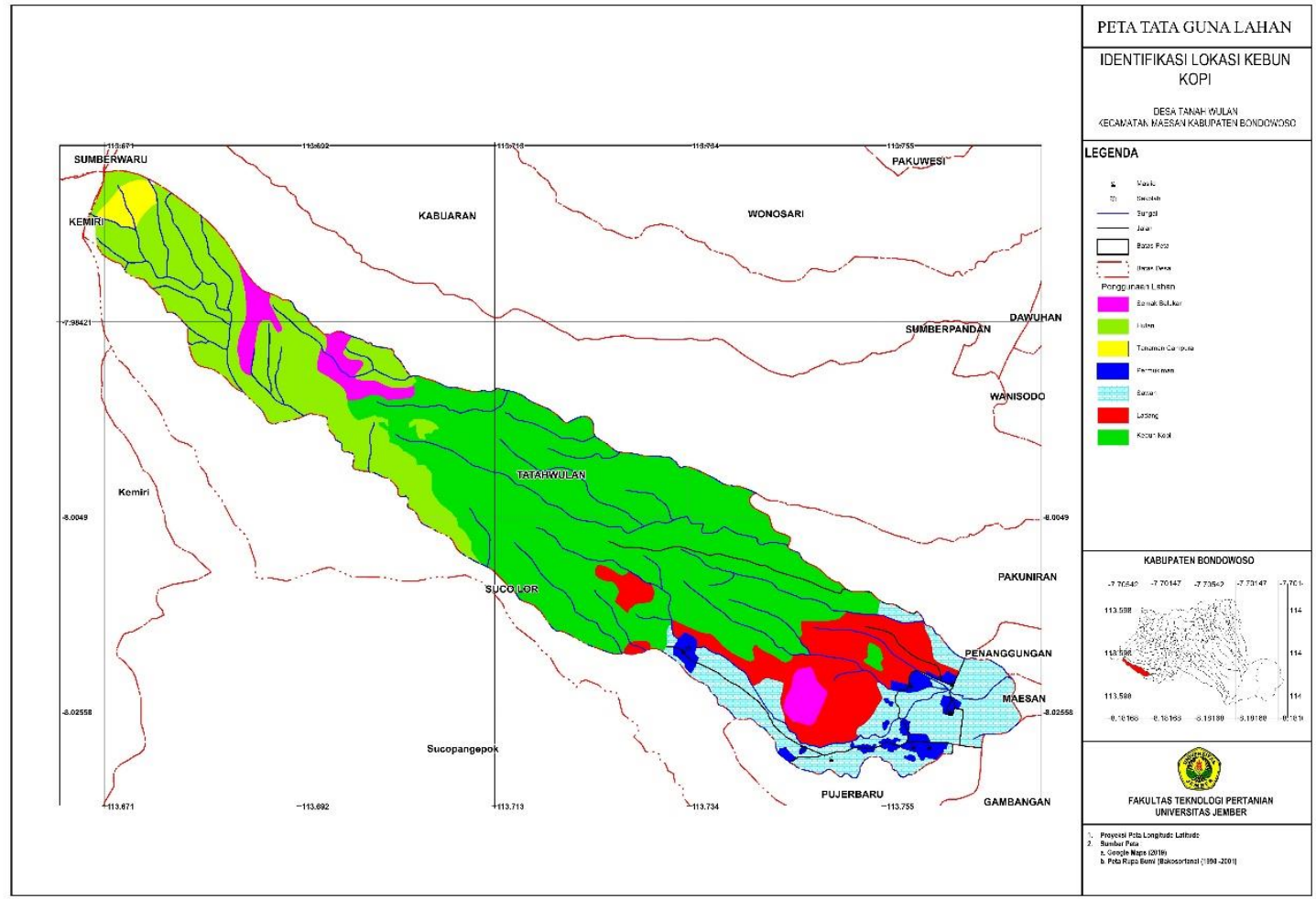

Gamabar 2. Peta Tata Guna Lahan Desa Tana Wulan

Dari hasil interpretasi peta tata guna lahan masih dapat diketahui lokasi dari kebun kopi di desa Tanah Wulan. Selain untuk identifikasi lokasi kebun kopi peta tata guna lahan jga digunakan untuk mengidentifikasi tutupan lahan di Desa Tanah Wulan. Luas total kebun kopi desa
Tanah Wulan yaitu 967,2 ha dengan luas kebun kopi arabika 354,5 ha dan luas kebun kopi robusta 625,7 ha. Berdasarkan peta tata guna lahan beberapa lahan masih dapat dimanfaatkan untuk perkebunan kopi seperti lahan sema belukar. 


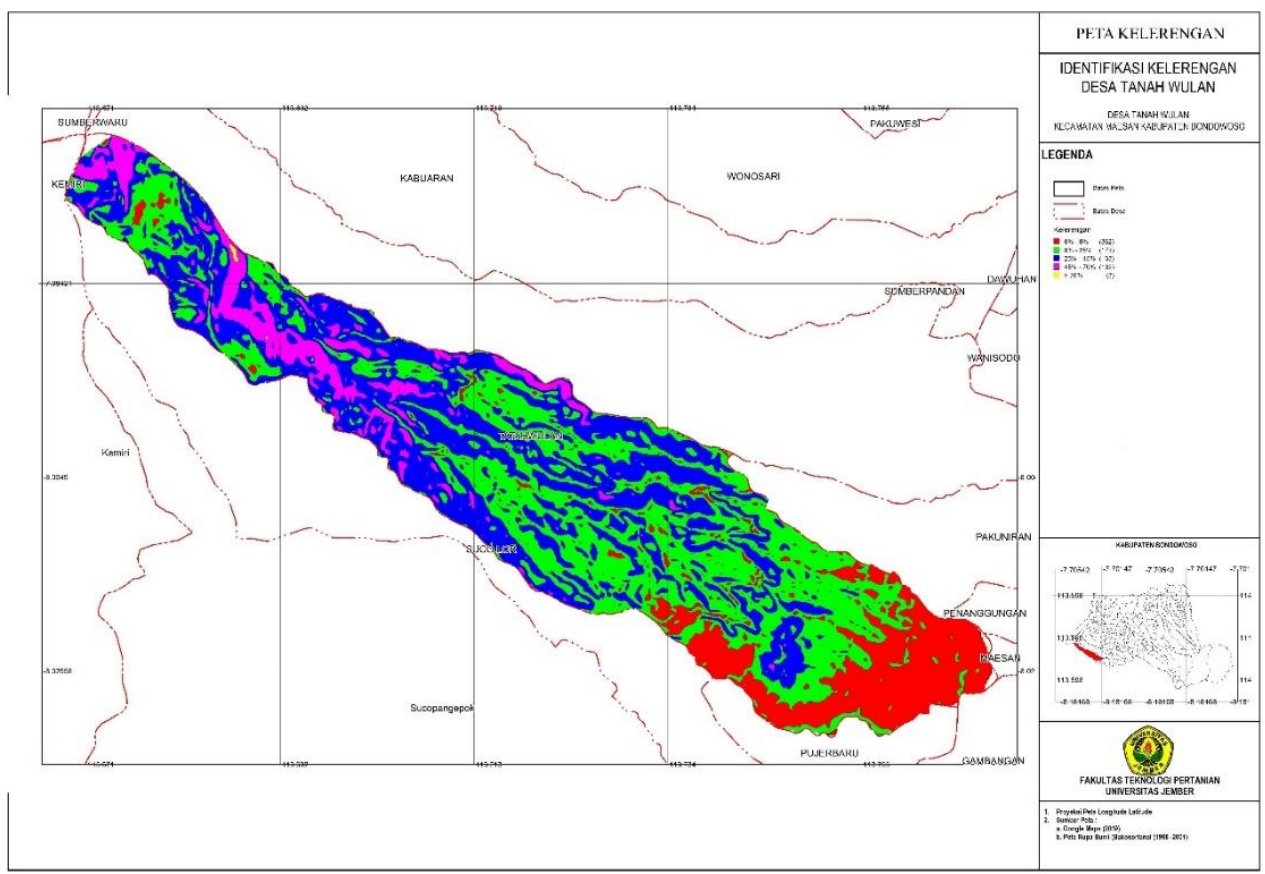

Gamabar 3. Peta Kelerengan Desa Tanah Wulan

Hasil interpolasi data kontur menghasilkan peta kelerengan yang digunakan untuk menentukan lokasi yang sesuai untuk tanaman kopi. Tanaman kopi disarankan untuk ditanam dengan kelerengan kurang dari 45\%. Dari hasil analisi kelerengan daerah dengan kelerengan lebih dari 45\% memiliki luas total 183,7 ha yang kebanyakan berada pada ketinggian lebih dari $1000 \mathrm{~m}$ dpl.

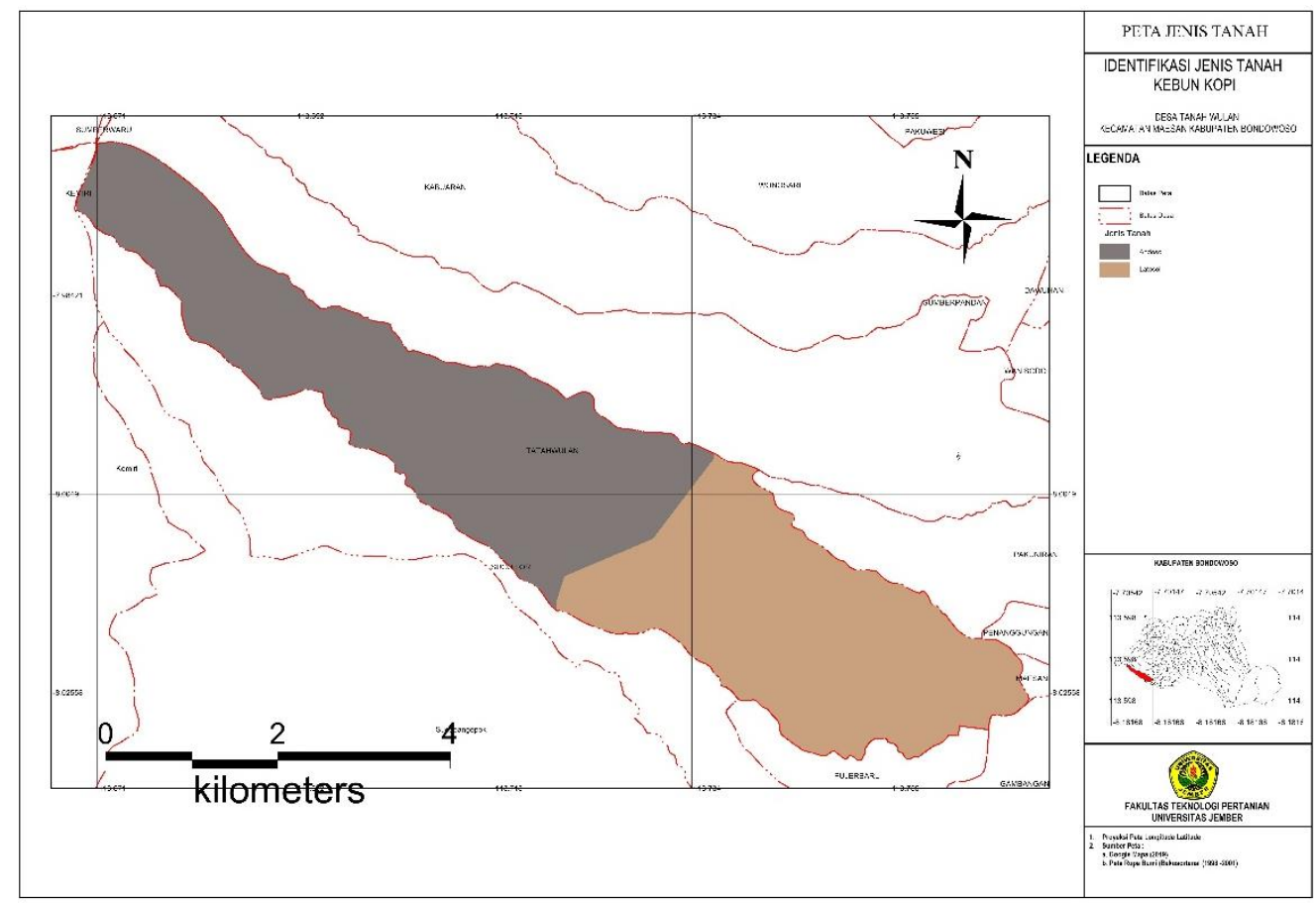

Gambar 4. Peta Jenis Tanah Desa Tanah Wulan 
Jenis tanah di Desa Tanah Wulan merupakan tanah andosol dan latosol. Kedua jenis tanah tersebut memiliki karakteristik yang sesuai untuk tanaman kopi yaitu bertekstur lempung dan liat.

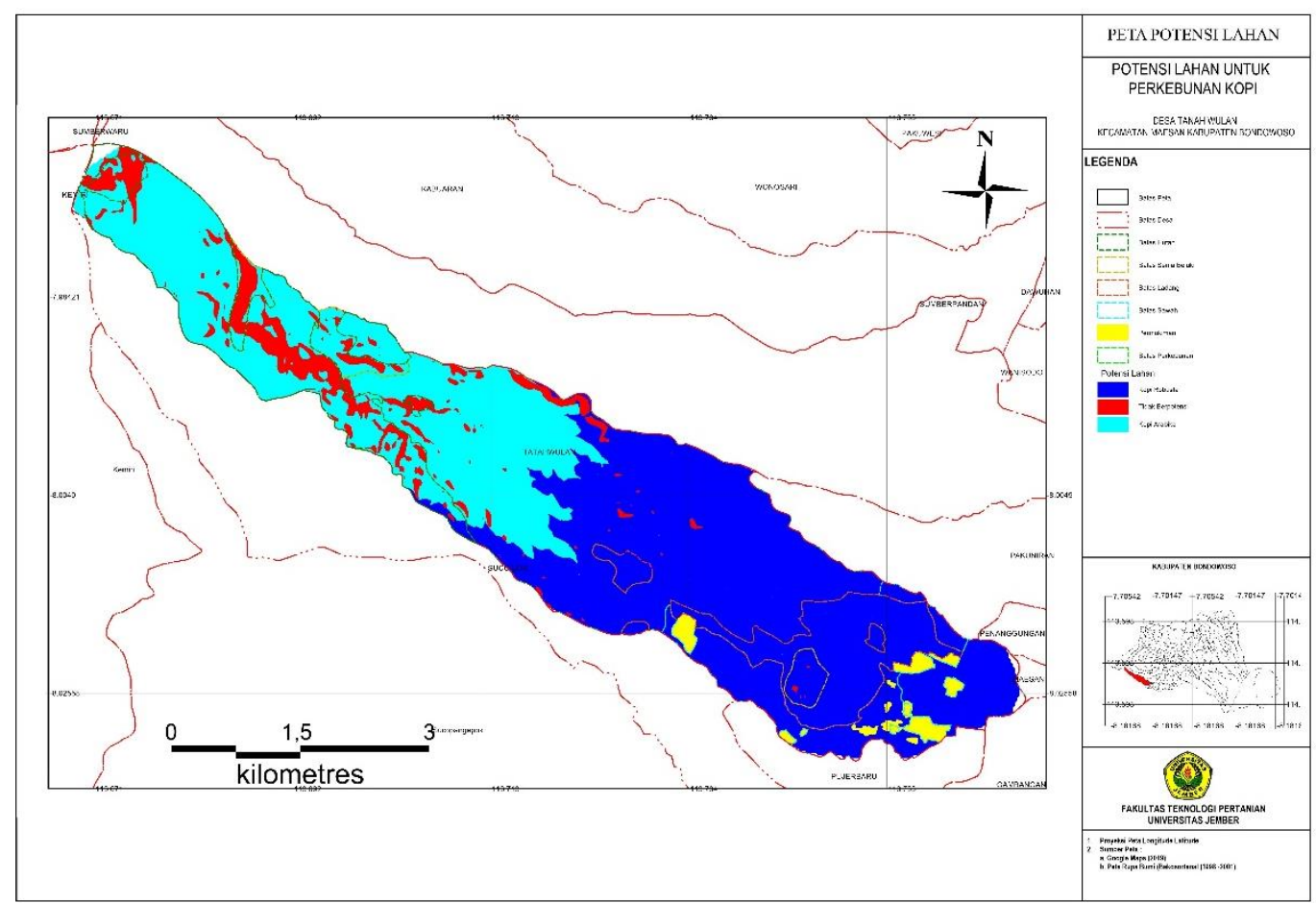

Gamabar 5. Peta Potensi Lahan Untuk Tanaman Kopi di Desa Tanah Wulan

Peta potensi lahan memuat informasi tentang lokasi yang sesuai tanaman kopi berdasarkan ketinggian, kelerengan, dan

jenis tanah. Hasil analisis potensi lahan yaitu sebagai berikut

Table 1 luas lahan potensia untuk tanaman kopi

\begin{tabular}{ccccc}
\hline Jenis Kopi & Lahan Sesuai (ha) & $\begin{array}{c}\text { Lahan Tidak } \\
\text { Sesuai (ha) }\end{array}$ & $\begin{array}{c}\text { Yang Sudah } \\
\text { Dimanfaatkan } \\
\text { (ha) }\end{array}$ & $\begin{array}{c}\text { Yang Belum } \\
\text { Dimanfaatkan } \\
\text { (ha) }\end{array}$ \\
\hline Kopi Arabika & 696 & 164,5 & 341,5 & 354,5 \\
Kopi Robusta & 652,46 & 18,7 & 625,7 & 26,76 \\
\hline
\end{tabular}

Dari hasil analisis potensi lahan desa Tanah Wulan, lahan yang dapat dimanfaatkan untuk perkebunan kopi seluas 381,26 ha yang kebanyakan berada pada ketinggian lebih dari $1000 \mathrm{~m}$ dpl. Jenis tanaman kopi yang sesuai pada lokasi tersebut yaitu jenis kopi Arabika. Dari hasil analisis potensi lahan didapatkan hasil lahan yang berpotensi untuk perkebunan kopi arabika hanya terkelola sebanyak 49\% sedangkan untuk lahan robusta sudah dikelola sebanyak 95\%. Potensi lahan untuk perkebunan kopi arabika berada pada lokasi hutan dan semak belukar dengan total luas 354,5 ha. Potensi lahan untuk tanaman kopi jenis robusta yaitu 26,76 ha dan berada pada lahan dengan tanaman semak belukar. Pembukaan lahan baru perkebunan kopi arabika perlu lebih diperhatikan karena lokasi yang berada pada daerah hutan. Lahan yang tidak sesuai untuk tanaman kopi jenis arabika seluas 
164,5. Lahan tersebut tidak sesuai karena memiliki kelerengan $>45 \%$ sehingga diindikasi pada lokasi tersebut akan lebih mudah mengalami erosi.

\section{KESIMPULAN}

Berdasarkan penelitian tersebut, dapat ditarik kesimpulan sebagai berikut:

1. Lahan yang berpotensi untuk dijadikan sebagai perkebunan kopi di Desa Tanah Wulan tersebar hampir diseluruh desa dengan potensi pengelolaan untuk kopi jenis Arabika seluas 354,5 ha dan 26,76 ha untuk jenis kopi robusta.

2. Pembukaan lahan untuk perkebunan kopi perlu memperhatikan faktor kelerengan lahan untuk mengurangi dampak erosi.

3. Tanah di desa Tanah Wulan berjenis andosol dan latosol yang memiliki karakteristik sesuai dengan syarat tumbuh tanaman kopi yaitu bertekstur lempung atau liat.

\section{DAFTAR PUSTAKA}

Kementrian Perdagangan. 2018. Perundingan Kopi Internasional International Coffee Organization (Ico).http://ditjenppi. kemendag.go.id/index.php/apecoi/organisasi-komoditiinternasional/ico. Diakses pada 02 Mei 2019.

Mulyana, Wahyu. 1982.Segi Praktis Cocok Tanam Kopi. Semarang: CV. Aneka.

Supriadi handi. 2017. PERSIAPAN DAN KESESUAIAN LAHAN TANAMAN KOPI - Kesesuaian Lahan.

http://balittri.litbang.pertanian.go.id/ index.php/berita/info-teknologi/474persiapan-dan-kesesuai-lahantanaman-kopi?start=1. Diakses tanggal 29 agustus 2019.
Syamsulbahri. 1985. Bercocok tanam tanaman perkebunan tahunan. Malang. 